\title{
Tools for Designing Experience: Repurposing Design Resources for the Emerging Experience Economy
}

\author{
lan Willcock \\ University of Hertfordshire \\ UK \\ i.willcock@herts.ac.uk
}

\begin{abstract}
The creative industries are following the trend exhibited in other fields of economic activity by increasingly focussing on selling 'experiences' rather than 'objects'. Typically, this shift results in immersive products which include elements such as narrative, space, media and/or performance within an overall presentation characterised by audience agency and an aim of sense-making.
\end{abstract}

\begin{abstract}
Experience Design, the planning and production of these experience-centred, immersive productions, is a new and essentially interdisciplinary academic field meaning that almost all current practitioners originally trained in a different (albeit related) single area (e.g., architecture, theatre, UI design, etc.) and have developed their interdisciplinary expertise through a process of individual research, experience and reflection. This necessarily limits the availability of suitably skilled practitioners and there is a growing sense that appropriate training needs to be developed to support the continued expansion of the sector.

This paper aims to support this pedagogical development process by examining a range of planning processes and tools used the disciplines which contribute to experience design together with recently developed tools from the experience economy. Suggestions of ways existing tools might be extended to accommodate the wider range of media and contexts typically encountered in an experience production are presented. An 'experience model' is proposed to support the analysis and identification of key elements of immersive experiences and the paper concludes with a provisional identification of a core set of key design tools and techniques which experience designers might employ across the range of current immersive practice.
\end{abstract}

Digital media design. Experience design. Interdisciplinary practice. Planning tools. User-centred design.

\section{INTRODUCTION TO EXPERIENCE}

"In 1970, futurist Alvin Toffler pointed to a paradigm shift that would deeply affect goods and services in the future and would lead to the next forward movement of the economy. Calling it a strange new sector, he named it the experience industries. Three decades later, Pine and Gilmore echoed his belief by arguing that we have moved out of the service economy and into what they identified as the experience economy." (Knutson \& Beck 2004, p. 23)

The shift from objects to experiences, first identified by Toeffler and then described in detail by Pine and Glimore, reflected how (retail) businesses have changed from servicing the patterns of postFordism, where individual acts of consumption provided the outward facing forms of individuality, to an emerging model where consumers engage in economic activity to acquire the actual life they want rather than its appearance and where the successful selling of products or services requires an accompanying theatrical dimension (Pine and Gilmore 1999).

The creative industries are also following this trend by increasingly focussing on selling 'experiences' rather than 'objects' to their customers. This shift results both in changes to the promotion and consumption of existing products, an increase in cross platform marketing and the involvement of audiences over longer periods through pervasive, social media-based advertising and participative activities. The rise of experience products within the creative industries has also produced a new 
range of immersive products which necessarily draw on a range of media and design disciplines to achieve their overall effect as they include elements such as narrative, space, media and/or performance within an overall presentation characterised by audience agency and an aim of sense-making. These latter products, characterised by experience being at their heart, are produced in the UK by organisations forming a subset of the local creative economy - a group increasingly identified and categorised as being within the Experience Economy.

\begin{abstract}
"ExperienceUK.org is the online Directory of UK companies in the experience economy that supply museums, theme parks, visitor attractions, live events, aquariums, zoos, etc. worldwide." (ExperienceUK n.d.)
\end{abstract}

The field of design activity this paper seeks to address can be identified as that concerned with producing immersive events whose aim is to provide pleasurable meaningful experiences for audiences using place, communication (often involving media or performance), and time, with the involvement of some degree of audience agency.

As might be expected for a newly emergent area of activity, the study of the practice of experience design is also a relatively new academic field. It is characterised as an essentially interdisciplinary field of study which draws on several precursor design traditions reflecting the range of practices that are themselves often used within the production of experience events; architecture, theatre, film, visual communications, digital media, interactive systems and games to name a few. The novelty of the field also means that almost all current practitioners originally trained in a different (albeit related) single area (e.g., architecture, theatre, UI design, etc.) and have developed their interdisciplinary expertise through a process of individual research, experience and reflection. This necessarily limits the availability of suitably skilled practitioners; alongside the increasing attention on the experience economy because of its increasingly significant economic importance, there is a growing sense that appropriate training needs to be developed to support the continued expansion of the sector (Creative and Cultural Skills 2015, p. 13).

This need for trained practitioners in turn requires academics to develop courses and to ensure that a firm theoretical basis for the practice of experience design is developed together with appropriate tools and methodologies which can support professional working. Following from the nature of the experience discipline itself, it can be expected that these will be essentially interdisciplinary, capable of operating at the intersection of the different practices which make up contemporary immersive experience design and of unifying, or at least focussing, them on the applications required to produce successful, enjoyable and engaging experiences for audiences.

\section{A TAXONOMY OF PLANNING TOOLS}

In the search for design tools which will support the development of effective experience products, bearing in mind the range of means employed and the interdisciplinary nature of the topic, one needs to develop a generalised model of what designers are doing when they move from the initial aims established at the outset of a project through to the specifications for the final product. Unsurprisingly given the number of disciplines that feed onto experience design, there are a great many tools and methodologies that might potentially have some application in the creation of experience events. To make useful evaluations of processes and resources originally employed in, and related to the materiality of, a single (or small range of) design practice and to then identify which techniques might be used within the interdisciplinary domain of experience design, there is a need to establish a model of the design process which can accommodate these constraints.

The search for a generic model of the modern design process, a process which is characterised by the activity of designing being separated from that of making and where the outcome of the design process is not an object, but rather a set of specifications for making the object, is not a new one, examples include Alexander (1964), Gregory (1966) and Pugh (1990) through to Lawson (2006) and the Design Council (2015). Those wishing to incorporate digital tools within the design process have continued this work (Jing \& Yang 2015); a comprehensive and useful survey of engineering and creative design processes can be found in Howard, Culley \& Dekoninck (2008). There are also useful and insightful models proposed which are based in specific design practices such as Goldschmidt (1991) for architecture and Lamb and Kallal (1992) for fashion.

Most of these models of the design process, both generic and domain-specific, use conceptual processes, products or activities as organising principles, however the survey presented below rather takes as its starting point the different dimensions of design which are common to both discipline-specific processes and to the interdisciplinary process of experience design; the intended users or audience, the features or affordances the product must offer, and the appearance it will present to users or audiences. In other words, this paper will look at how different 
disciplines approach answering the basic questions about any product; who is it for, what must it do and what should it be (i.e., look/sound/feel) like?

It should be noted that there are some very important aspects of design practice, particularly the organisation and duration of iterative development activities, that are not dealt with here, largely for reasons of brevity. Similarly, processes of ideation, those techniques for developing initial ideas to the point where a defined project with identifiable overall goals emerges as a material, semi-public entity which can be shared and discussed with a design team, are also excluded as there is a high degree of similarity amongst disciplines between the techniques used (brain storming, algorithmic methods, focus groups, collaborative design, etc.). Given the large extent of overlapping practice, it can be reasonably expected that such approaches will also work effectively for the initial development stages of experience products, for example the co-production approach of Derby Museums demonstrates how collaborative design approaches can be successfully applied to the Experience Design process (Derby Museums n.d.)

\section{CURRENT TOOLS}

To support the pedagogical development process required to meet the need for appropriately trained design professionals identified above, this paper will initially examine a range of planning processes and tools used the disciplines which contribute to experience design however, it is also important to recognise that a range of hybrid planning tools, often of great sophistication (Derby Museums 2014, Vision XS), have been developed within the emerging experience industry.

\subsection{People - who is the product for?}

The contributing disciplines to experience design use a variety of terms (audience member, user, player, visitor, etc.) to identify who the designer is aiming the product or artefact at, the different words reflecting something of the assumed relationship between product and consumer. Don Norman in his influential The Design of Everyday Things articulated the importance of this when he advocated, "user-centred design, a philosophy based on the needs and interests of the user, with an emphasis on making products usable and understandable." (Norman 1988, p. 188). The importance of the user in developing effective designs makes reflecting their characteristics especially important during the design process; however, this can be problematic since:

"In many areas of design, there has been a tradition of 'second order thinking': that is, of designers using their own intuitions about what constitutes good design and of using themselves and their own preferences as reasonable approximations of what their potential customers or end-users might want." (van Leeuwen \& Westwood 2008, p. 158)

To counter this (often unconscious) tendency to design or produce for oneself, three main approaches towards ensuring the target user influences the design process have emerged; empirical, demographic and persona-based. It is worth noting that the adoption of these approaches is not spread evenly across all the areas of practice that make up experience design; different disciplines tend to employ different types and mixes of audience envisioning tools.

Empirical approaches tend to be based on heuristics and principles derived from the physical and cognitive capabilities of users and implicitly tend to ascribe the effectiveness of the relationship between designed object and human solely to features of the object rather than any dynamic dialogue or experiential factors. Norman's usercentred design principles derive from using human characteristics (grip, shape, perception, thought patterns) as a required constraint in the process of designing objects and systems, an approach given a statistical data-driven basis in fashion and architecture where precise, models of the human form are used to inform designs. The first generation of Human Computer Interaction $(\mathrm{HCl})$ theories such as Fitts' law (Fitts 1954) took a similar approach inflected by Shannon and Weaver's Information theory (Shannon \& Weaver 1949).

The demographic approach towards ensuring that the target audience affects the design outcome rests on a supposed linkage between a given demographic identification (gender, lifestyle, media preferences, etc., see The Audience Agency 2017) of a sector of society and the likely appeal of the final designed outcome to an individual within that identified group. However, the mechanism and evidence for this linkage is often unclear beyond the obvious intertextual relationships between the endpoint of the design process and the existing cultural familiarities of the identified group (Lumpkin and Darden 1982). While this approach is still very widely used particularly in marketing and narrative media forms, as products become increasingly individualised and experience-based, there is a recognition that demographics may become increasingly less useful;

"Current audience models might be a useful 'first cut', but if designers are to properly address the play needs of its mass market then better psychological profiles informing more 
sophisticated audience models are needed."

(van Leeuwen \& Westwood 2008. p. 160).

Personas are imaginary, individual character descriptions constructed from real data to provide a tool for empathetic design (Kouprie and Visser 2009). Through specifying the likes, dislikes and approaches to life ('something they would say' is a feature of most personas) of the character in a vivid way, they are intended to help take the designer out of their own personality and enable them 'act out' that of a different person, to predict more accurately how they will react to a specific design feature or implementation. The distinguishing features that comprise the persona vary, from lists of basic likes and dislikes together with a photograph and characteristic saying, through to complex specifications influenced by psychology (Xtensio).

\subsection{Communication and Affordances}

At a macro level, almost all design begins with a set of aims it seeks to accomplish. From identifying these overarching goals, a design process will go on to develop a more finely grained approach; how will the product achieve the overall aims and, in progressively more detail, how does the contribution of each element assist in realising that overall vision? For location or time based design practices, this fine grain will identify the different stages in the journey or experience; places, scenes or chapters. For those practices which require useragency, there will be a requirement to identify and specify the content and extent of the dialogue between artefact and user at each stage. Text is often used initially in many disciplines before the detailed planning of the component elements is carried out to provide an essentially descriptive account of the approach to the underlying (user) narrative. Examples include scenarios from UX design (short text-based narratives describing the context, motivations and content of a user's engagement with an interactive system), treatments and plot summaries and use summaries for locations.

Design traditions all have their own individual ways to allow designers to visualise and plan the detail of the sequence of connections between users or audiences and the artefact. Kalback and Kahn propose the term alignment diagrams (Kalback and Kahn 2011, p. 2) for these, examples include user journeys in UX design, service blueprints from service design and 'canvas' approaches from retail and business planning. An important precursor of the user journey in UX design is the task model - a dynamic analysis and planning tool showing for a given task or goal what an interactive system must provide at each stage of the interactive episode, how the overall interaction can be divided into phases and how each stage progresses to the next together with information about the user's behaviour and motivations, see Figure 1.

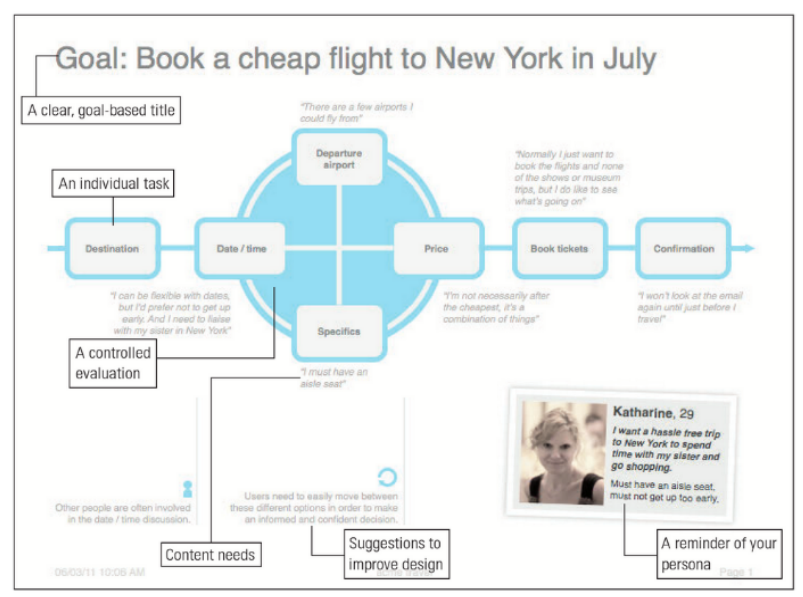

Figure 1 - Task Model example - (c) cxpartners 2011 (Caddick \& Cable 2011, p. 50)

Where audience agency is less important in the design of the artefact (film, architecture, theatre), the planning and design of the audience's contact with the artefact is often approached through mix of text and image which summarises content as a set of elements defined by the materiality of the medium (shots, scenes, chapters, locations). Examples of these approaches include storyboards, and graphical narrative-content maps.

These tools all allow the relationship between the user and product to be segmented and for each segment to be planned and optimised using relevant theory and experience. For film, games and other narrative forms, narrative theories and frameworks (Richardson 2000, Reagan et al. 2016) or games design 'lenses' (Jenkins 2004, Schell 2008) will be used to shape the audience's experience, identifying what the narrative has to accomplish at the different points in the overall experience or how rewards should be provided to encourage prolonged engagement and immersion.

Additionally, some design disciplines make use of mainly diagrammatic (but not necessarily representational) methods to enable the structural design of projects; maps and plans. These typically concentrate on constructional, connective or other details, leaving out aspects of surface such as texture, colour or layout so that underlying detail can be shown. Architecture's use of plans is core to the way the discipline communicates designs but similar approaches are found in other areas. UX and information design use the site map, "a diagram showing the structure of a site" (Newman \& Landay 2000 , p. 268) in conjunction with a set of wireframes; stylised diagrams which are used to communicate aspects of design and functionality for each screen or page of an interactive system. 
Film and theatre use the blocking diagram which shows the movements of actors (and cameras and lights, etc.) for a given scene (Stanley \& Monta 2007).

In contemporary experience design, the dialogue between visitor and the various elements making up the production is considered using the idea of the touchpoint; an 'atomic' unit of experience which allows the planning and evaluation of overall audience experiences to be approached as the sum of a sequence of experience-components (touchpoints), each of which can be planned and analysed separately. The term and concept were taken originally from retail and service design, where a touchpoint is defined as any point of contact between a retailer and a customer (Walters 2016) which serves to form a customer's opinion of the brand or organisation.

Tools have been developed to assist the designer of experience attractions. Vision XS (2015a) have produced a range of powerful proprietary planning and evaluation tools with associated underlying models using an algorithmic approach populated by experimental data sources from psychological studies. They can use these tools both predictively, for planning new experience productions and analytically to evaluate the effectiveness of existing experience projects:

"A Visitor Journey Analysis is a way to describe all the experiences a visitor has on your site and the emotional responses they provoke - from their first impression of your buildings, to speaking to staff, taking part in an activity or receiving a service. The visitor experience consists of interconnected touchpoints, which together contribute to a visitor's overall feelings about their trip." (VisionXS 2015b)

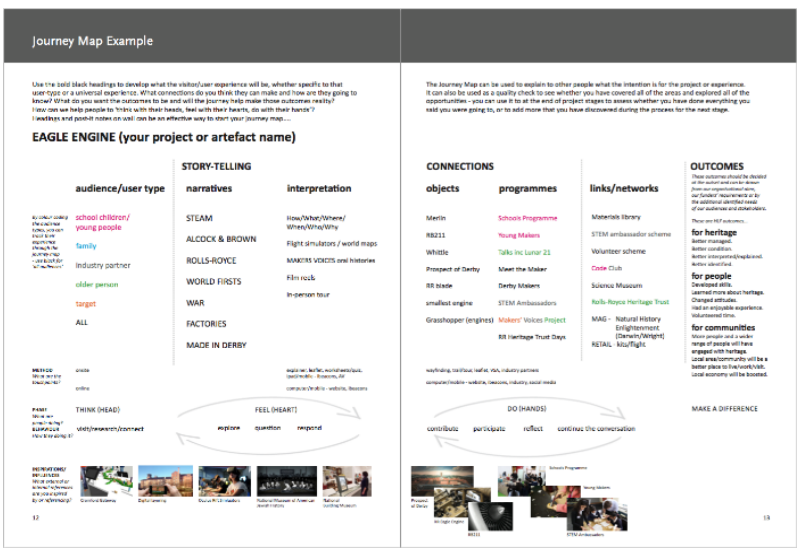

Figure 2: Journey Map (c Derby Museums (Derby Museums 2014, p. 12)

In contrast to this algorithmic, data-driven approach, Derby Museums have developed the Journey Map (see Figure 2), a mix of graphics and text with prompts which is designed to help identify the ways audiences, narratives and objects or locations will produce experience outputs (learning, reflection, changed attitudes, pleasure). Part of their collaborative experience design methodology (Derby Museums 2014), the Journey Map would seem to be most useful relatively early in the experience design process.

\section{Visual Presentation}

In contrast to the tools discussed in the previous section, designers also need to specify how the artefact will present or manifest itself to the audience or user; what it will look or sound like. Typically, the development of the final visual identity will proceed through several stages, each supported by different tools. Once the basic visual research has been completed, most disciplines have a visual prototyping phase, a set of practices which convey aspects of the final product's visual appearance to clients and the wider development team. In UX design, visualisations and clickthrough prototypes are used, theatre and architecture have typically used physical models, and product and installation design might produce partial or scaled mockups. All these practices are currently undergoing change; increasingly powerful interactive development systems mean that the production differences between a click through prototype and a fully functional system are becoming smaller and smaller. Rapid prototyping techniques mean that producing fully realised artefacts is less costly and that changes can be accommodated later (and more often) in products development cycles. Digital visualisation has, thanks to the increasing integration between modelling and visualisation tools, become a comparatively easy process providing high quality, even immersive, simulations of spatial designs (Lumion n.d.). While physical models are still a feature of spatial design prototyping (albeit increasingly produced using 3D printers and laser cutters), 3D models and screen or fully immersive visualisations including fly-throughs and simulations are becoming standard tools for communicating and evaluating architectural designs.

Time-based media such as film and animation use the Storyboard as a primary means to communicate the visual content. While the basic format of shot by shot drawings, usually with comments about effects and transitions, used for linear, observational media is familiar, the format has been extended in interesting ways to accommodate the differing demands of new media forms. $A \Phi E$, an immersive dance and virtual reality company, plan their immersive productions as a sequence of narrative 'pockets' and extend the conventional dimensions of the storyboard to accommodate the needs of a form of storytelling in 
which position and audience agency were elements of the overall composition,

\begin{abstract}
"There were depth and height in our storyboard, audience movement in the script, locations that could be experienced in $360^{\circ}$ " (Fourmi et al. 2016, p. 196)
\end{abstract}

To help students plan gallery installations using a mix of media, physical artefact and user activity to create individual experiential narratives, Alan Peacock has developed the User Centred Storyboard (UCS) (Peacock 2017). The UCS uses significant events in the user's relationship with the work to segment the overall use-narrative and for each phase provides a visualisation from the user's perspective together with comments on what is being experienced as well as the imagined thought processes and responses of the user.

\section{REPURPOSING TOOLS FOR DESIGNING EXPERIENCES}

Many of the tools and approaches covered above can be directly applied to the experience design process, sketching and mood boards and the use of scenarios to begin the process of moving from the outline project aims towards the detailed specification of each of the constituent touchpoints. Sketching can be extended using the digital sketch, deliberately unfinished small-scale media artefacts which are rapidly produced allowing for the exploration of aspects of presentation or interaction without the investment of significant time or other resources. Such a technique is already used in animation as animatics, rapidly produced, low fidelity illustrations of the planned approach to animation.

Using personas as a means of informing predictions of audience behaviour are an area which could be more widely adopted. There is interesting work (Schäfer et al. 2014, Sieben et al. 2017) being done on combining big data approaches to crowd simulation with personas to produce more accurate and individualisable pictures of the ways visitors or audiences might behave. Especially in a field of application which is concerned with sense-making, treating all visitors as essentially similar members of a defined group will tend to produce poor design decision-making as individual diverge from this notional 'norm'.

The Derby Museums' Journey Map (fig. 2) provides an effective tool for collating the conceptual and content of productions and relating these to narratives and aims. However the methodology for developing further detail, for drilling down to the specific overarching narrative(s) and then identifying the requirements for each of the touchpoints which will communicate that story are less well defined; this step is currently managed through text-based, descriptive strategies. Stories are written which form the narrative backbone of the planned experience project. From this, experience designers use mapping as a part of their process; typically, a floorplan of the area is overlaid with the major sectors of the overall narrative to be communicated, establishing the correspondence between location and story for subsequent, even more detailed work. Once touchpoints or story-segments have been identified, the user-centred storyboard and blocking diagrams can be used to provide the detail. At this point, alignment diagrams of the type found in retail or UX design will, with an expansion in the range of relationships between customer and product to encompass the range of communications and activities used in experience design, be highly useful in planning and evaluating the visitor's experience journey.

\section{THE EXPERIENCE MODEL}

The gap in the process described above lies between the Journey Map with its high-level collation of aims, audiences, objects and outcomes, and the visitor journey and user-centred storyboard which require touchpoints to have already been identified. What is needed is an extension of the UX Task Model, a method for developing and refining the overall experiential narrative structure to the point where its constituent sections and their individual aims and requirements can be identified.

The proposed experience model is a hybrid diagrammatic/textual form which supports the analysis of the stages in a visitor's engagement with an experience product together with the transitions between those stages. It is thus concerned with the unfolding of an overarching narrative as a series of touchpoints and for each, allows the designer to identify in outline the specific narrative element(s), the media and other content required together with the desired outcomes and audience reactions the touchpoint is intended to engender. It should be a dynamic document, which is progressively refined through testing and input form the design team, but as it matures, it will identify each of the touchpoints within an overall experience with increasing certainty in terms of story, activities and emotional resonances.

\section{CONCLUSION}

There are a wide range of planning tools used in the range of design disciplines which contribute to experience design and many of them are applicable, with extensions, within this emerging interdisciplinary practice. While individual designers and studios will have their own preferences and 
workflows, it is possible to provisionally identify a core set of key design tools which experience designers might employ generally in the following categories:

- Audiences: persona approaches, personainflected crowd modelling.

- Communication and affordances: Journey Maps, Experience Model, Scenarios, Narrative map, Visitor Journeys

- Visual presentation: User-Centred Storyboard, Architectural plans, Physical and digital models, visualisations, simulations.

It is not imagined that all these tools will be used in any one project, or that others will not be used, or that their use will not be iterative and necessarily involve feedback between the various aspects of designing experiences as the final identity of the project emerges. Design for audiences, especially the wide ranging, complex interdisciplinary design associated with creating effective, meaningful and enjoyable experiences is difficult precisely because of the wide range of factors involved, the occasionally unpredictable actions of visitors, and the fragility of maintaining audience immersion and focus. It is hoped that providing additional resources to help experience designers in their work will support and encourage the creative development of the experience economy as a whole.

\section{REFERENCES}

Alexander, C. (1964) Notes on the Synthesis of Form. Harvard University Press.

Creative \& Cultural Skills (2017) Building a Creative Nation: The Next Decade. Research Report. Creative \& Cultural Skills, UK.

http://www.ccskills.org.uk/ten-years-ahead

(accessed 7 May 2017).

Caddick, R. and Cable, S. (2011) Communicating the User Experience a Practical Guide for Creating Useful UX Documentation. Chichester, West Sussex, U.K.: Wiley.

Derby Museums (2014) Derby Museums HumanCentred Design Handbook. Derby Museums, UK. https://www.derbymuseums.org/wpcontent/uploads/2016/01/Derby-Museums-HCDHandbook.pdf (accessed 25 March 2017).

Derby Museums (n.d.) Re:Make Museum. [Online blog]. http://remakemuseum.tumblr.com/?og=1 (accessed 26 March 2017).

Design Council (2015) The Design Process: What Is the Double Diamond? Design Council, UK. http://www.designcouncil.org.uk/news- opinion/design-process-what-double-diamond (accessed 12 March 2017).

Experience UK (n.d.) International Business Directory for the UK Attractions Industry. Experience UK. http://www.experienceuk.org/pages/about/2 (accessed 16 September 2016).

Fitts, P. M. (1954) The Information Capacity of the Human Motor System in Controlling the Amplitude of Movement. Journal of Experimental Psychology, 47 (6), pp. 381-391.

Fourmi, E., Hon, J., and Nakamura, A. (2016) Whist: Dance Theatre and Virtual Reality. In J. P.Bowen, G. Diprose \& N. Lambert (eds.), EVA London 2016: Electronic Visualisation and the Arts, pp. 195-196. Electronic Workshops in Computing, BCS. DOI: 10.14236/ewic/EVA2016.39

Friess, E. (2012) Personas and Decision Making in the Design Process: An Ethnographic Case Study. In: Proceedings of the SIGCHI Conference on Human Factors in Computing Systems, 2012. New York, NY, USA: ACM, pp. 1209-1218.

Goldschmidt, G. (1991) The Dialectics of Sketching. Creativity Research Journal, 4(2) January, pp. 123-143.

Gregory, S. A. (1966) Design and the Design Method. In: M.I.Chem.E, S. A. G. B. S., C.Eng ed., The Design Method. Springer US, pp. 3-10

Howard, T. J., Culley, S. J., and Dekoninck, E. (2008) Describing the Creative Design Process by the Integration of Engineering Design and Cognitive Psychology Literature. Design Studies, 29(2) March, pp. 160-180.

Jenkins, H. (2004) Game Design as Narrative Architecture. Computer, 44, pp. 53-60.

Jing, D. and Yang, H. (2015) Creative Computing for Bespoke Ideation. In: IEEE 39th Annual Computer Software and Applications Conference, July 2015. vol. 1. pp. 34-43.

Kalbach, J. and Kahn, P. (2011) Locating Value with Alignment Diagrams. Parsons Journal of Information Mapping, 3(2), pp. 1-11.

Knutson, B. J. and Beck, J. A. (2004) Identifying the Dimensions of the Experience Construct. Journal of Quality Assurance in Hospitality \& Tourism, 4(3-4) February, pp. 23-35.

Kouprie, M. and Visser, F. S. (2009) A Framework for Empathy in Design: Stepping into and out of the User's Life. Journal of Engineering Design, 20(5) October, pp. 437-448.

Lamb, J. M. and Kallal, M. J. (1992) A Conceptual Framework for Apparel Design. Clothing and 
Textiles Research Journal, 10(2) January, pp. 4247.

Lawson, B. (2006) How Designers Think: The Design Process Demystified. Routledge.

Leeuwen, L. van and Westwood, D. (2008) Adult Play, Psychology and Design. Digital Creativity, 19(3) September, pp. 153-161.

Leung, E. B. L. (n.d.) Digital Experience Design. Intellect Books.

https://www.dawsonera.com/abstract/97818415028 $\underline{54}$ (accessed 19 August 2016).

Lumion (n.d.) Lumion - Overview. Lumion. https://view.mylumion.com (accessed 7 April 2017).

Lumpkin, J. R. and Darden, W. R. (1982) Relating Television Preference Viewing to Shopping Orientations, Life Styles, and Demographics: The Examination of Perceptual and Preference Dimensions of Television Programming. Journal of Advertising, 11(4) December, pp. 56-67.

Mostow, J. (1985) Toward Better Models of the Design Process. Al Magazine, 6(1) March, p. 44.

Newman, M. W. and Landay, J. A. (2000) Sitemaps, Storyboards, and Specifications: A Sketch of Web Site Design Practice. In: Proceedings of the 3rd Conference on Designing Interactive Systems: Processes, Practices, Methods, and Techniques, 2000. New York, NY, USA: ACM, pp. 263-274.

Norman, D. (1988) The Design of Everyday Things. Basic Books.

Peacock, A. (2017) The User Centred Storyboard. Unpublished teaching material.

Pine, B. J. and Gilmore, J. H. (1999) The Experience Economy: Work Is Theatre \& Every Business a Stage. Harvard Business Press.

Pugh, S. (1990) Total Design: Integrated Methods for Successful Product Engineering. Wokingham, England; Reading, MA: Prentice Hall.

Reagan, A. J., Mitchell, L., Kiley, D., Danforth, C. M., and Dodds, P. S. (2016) The Emotional Arcs of Stories Are Dominated by Six Basic Shapes. EPJ Data Science, 5(1) December.

Richardson, B. (2000) Recent Concepts of Narrative and the Narratives of Narrative Theory. Style, 34(2), pp. 168-175.
Sanders, E. (2002) From User-Centered to Participatory Design Approaches. In: Design and the Social Sciences. CRC Press, pp. 1-8.

Schäfer, C., Zinke, R., Künzer, L., Hofinger, G., and Koch, R. (2014) Applying Persona Method for Describing Users of Escape Routes. Transportation Research Procedia, 2 January, pp. 636-641.

Schell, J. (2008) The Art of Game Design: A Book of Lenses. Morgan Kaufmann Publishers Inc.

Shannon, C. E. and Weaver, W. (1949) The Mathematical Theory of Communication. Urbana: Univ. of Illinois Press.

Sieben, A., Schumann, J., and Seyfried, A. (2017) Collective Phenomena in Crowds - Where Pedestrian Dynamics Need Social Psychology. arXiv:1702.07012 [physics], February. http://arxiv.org/abs/1702.07012 (accessed 7 April 2017).

Stanley, J. and Monta, M. (2007) Directing for Stage and Screen. Springer.

Takeda, H., Veerkamp, P., and Yoshikawa, H. (1990) Modeling Design Process. Al Magazine, 11 (4) December, p. 37.

The Audience Agency (2017) Audience Spectrum Pen Portraits. The Audience Agency. https://www.theaudienceagency.org/audiencespectrum/profiles (accessed 18 September 2016).

Thynne, M. and Willcock, I. (2016) Ecologies of Experience: A Survey of Contemporary Immersive Practices. Presented at: Digital Research for the Humanities and Arts (DRHA), 5 September, Brighton UK.

VisionXS (2015a) Visitor Experience Modelling. VisionXS.

http://www.visionxs.co.uk/services/visitorexperience-modelling/ (accessed 25 March 2017).

VisionXS (2015b) Visitor Journey Analysis. VisionXS. http://www.visionxs.co.uk/services/visitor-journeyanalysis/ (accessed 7 April 2017).

Walters, J. (2016) What IS a Customer Touchpoint? Customer Experience Consulting. http://360connext.com/customer-touchpoint/ (accessed 26 March 2017).

Xtensio (2015) How To: Create a User Persona. Xtensio. https://xtensio.com/how-to-create-a-userpersonal (accessed 6 April 2017). 